\title{
RELATIONSHIP AMONG E-SERVICE QUALITY, CULTURE, ATTITUDE, TRUST, RISK OF ONLINE SHOPPING
}

\author{
${ }^{1}$ Mohammad Al-Nasser, ${ }^{1}$ Rushami Zien Yusoff, ${ }^{2}$ Rabiul Islam and ${ }^{1}$ Abdullah Al-Nasser \\ ${ }^{1}$ School of Business Management, College of Business, University Utara Malaysia, Malaysia \\ ${ }^{2}$ School of Economics, Finance and Banking, College of Business, University Utara Malaysia, Malaysia
}

Received 2014-06-19; Revised 2014-06-22; Accepted 2014-10-14

\begin{abstract}
Purchasing is considered a risky business specifically in the online purchasing environment. The research was designed to fill the gap in the existing body of knowledge regarding attitudes and differences in electronic service quality perception between two different geographical and cultural countries-Malaysia and Saudi Arabia-regarding online shopping. Specifically, this research extended previous effort done in an online shopping context by providing evidence that high service quality increase consumers' trust perception, which in turn results in favorable attitude toward online shopping, with risk perception on consumer's trust. Findings indicated differences between Saudis and Malaysians in e-service quality perception. Also attitude toward online shopping was affected by e-service quality perception, but it had mediated effects through trust. Finally, researcher found that perceived risk moderated the relationship between e-service quality and trust. The findings provide practical suggestions for managers on how to develop consumer trust online and enhance purchase attitude even when customers have high risk perception. E-service quality should strongly influence trust for individuals with a higher perceived risk associated with online purchase in comparison to those with a lower perceived risk.
\end{abstract}

Keywords: E-service Quality, Culture, Attitude, Trust, Risk of Online Shopping

\section{INTRODUCTION}

\subsection{Definition of Culture}

An understanding of what culture is, its dimensions, definitions and conceptualizations are important for research on culture (Straub et al., 2002). Kroeber and Kluckhohn (1952) defined culture as patterns, explicit and implicit, of and for behavior acquired and transmitted by symbols, constituting the distinctive achievements of human groups, including their embodiments in artifacts. Leung et al. (2005) defined culture as "values, beliefs, norms and behavioral patterns of a group-people in a society for national culture, staff of an organization for organizational culture, specific profession for professional culture etc.

Definitions of culture range from the very comprehensive, as defined by Herskovitz (1955) as "the Corresponding Author: Mohammad Al-Nasser, School of Business Ma human-made part of the environment", to the highly focused, as defined by Geertz (1973) as a shared meaning system. Groeschl and Doherty (2000) stated that culture is complex and very difficult to define. They nonetheless defined it as consisting of several elements of which some are implicit and others are explicit. Most often these elements are explained by terms such as behavior, values, norms and basic assumptions. Culture proposed by some researchers as implicit artifacts or tacit such as basic assumptions, coherent sets of beliefs, ideologies, important understandings and shared sets of core values (Groeschl and Doherty, 2000).

\subsection{Dimensions of Culture}

Cultural dimensions are value constructs or psychological dimensions that can be used in describing an exact culture. Culture has many 
dimensions and many authors have provided different dimensions based on the different definitions of culture. Hofstede (1994) conducted the most comprehensive cross-cultural study to date in which he developed five cultural dimensions. This cultural dimension shows one of the important frameworks to understand the effect of culture on consumer behavior literature.

Since 1980, the Dutch management researcher, Geert Hofstede claims that people generally have mental programs that are invented and supported through their experience and that these mental programs consist of national culture. Hofstede (2001) has attempted to pinpoint the value dimensions 100,000 employees of multinational International Business Machines (IBM) located in 40 countries. Hofstede's dimensions have often been utilized in describing cultures. He identified four dimensions of power distance, uncertainty avoidance, masculinity and individualism. Alternatively, masculinity-femininity dimension gives an explanation about how a culture's dominant values are nurturing or assertive. Power distance is the distribution of impact within the culture. Uncertainty avoidance implies the culture's tolerance of risk and ambiguity acceptance. All these four dimensions have their basis on four principal issues in human societies. Based on Hofstede (1980) study, the dimensions signify the root elements of common structure in the system of cultures in countries.

Additionally, a fifth dimension along with the four above has been identified by Hofstede and Bond (1988), which is a Confucian dynamism referred to as short-term orientation versus long-term orientation to life. This dimension provides a description of cultures ranging from long-term values with persistence and ordering relations through status to short-term values in light of tradition and reciprocity in social relations. In 2010, the scores for this dimension were extended to 93 by Micheal Minkov who used the recent World Values Survey. This development has led Hofstede to define the sixth dimension: Indulgence versus restraint.

Through the analysis of data from over 93 countries, Hofstede showed that the mental programs indicates the presence of six underlying value dimensions on which the countries can be categorized into culture areas (Hofstede, 1984). These dimensions are shown below:

- Power distance: The degree to which power in equality is distributed among the society's members.

- Uncertainty avoidance: The degree to which organizational members perceive risks from uncertain situations or future uncertainty
- Individualism and collectivism: The explanation of the link between the individual and the collective whole that is revealed in the way people live within the society

- Masculinity and femininity: The level of roles division between men and women to which society places different stress on work goals and assertiveness versus personal goals and nurturance

- Long-term versus short-term orientation: The longterm orientation dimension can be interpreted as dealing with society's search for virtue. Long-Term Orientation (LTO) is defined by Bearden et al. (2006) in their research as "the cultural value of viewing time holistically, valuing both the past and the future rather than deeming actions important only for their effects in the here-and-now or the short term. Individuals scoring high in LTO value planning, tradition, hard work and perseverance" (Bearden et al., 2006)

- Indulgence versus restraint-indulgence stands for a society that allows relatively free gratification of basic and natural human drives related to enjoying life and having fun. Restraint stands for a society that suppresses gratification of needs and regulates it by means of strict social norms (Bearden et al., 2006)

Some researchers choose CVSCALE as others reported to the lack of reliability and validity of Hofstede's scale (Bearden et al., 2006). On the other hand, the CVSCALE has good reliability, validity and cross-cultural invariance. Moreover, the items are advantageous over Hofstede $(1980 ; 1994 ; 2001)$ items as the instrument applies to general consumer situations, as opposed to limited situations.

\subsection{Research on Culture}

Douglas and Craig (1997) examined the critical issues responsible for changing the dynamics of consumer behavior. The main findings of their theoretical study provided an important insight into the changing dynamics of consumer behavior on e-commerce. In addition, they found that culture is one of the most significant variables that influence the use of information systems, including electronic commerce. Kumar et al. (1998) noted that information systems and other technologies carry within them the culture of the developing nation and its programmers; it also carries within it the way of doing business in the area where it was developed. Thus, when these technologies are imported into alien cultures, they can fail due to cultural differences. 
Park and Jun (2003) investigated the relationship between culture and differences in the behavior of online buying. They carried out a cross-cultural comparison of on-line purchasing behaviors and examined the impacts of using Internet, perceived risks and innovation on a cross-cultural basis. In their study, they compared the factors affecting online buying behavior of Koreans and Americans. They demonstrated significant differences in Internet usage and the perceived risks of online shopping between the two cultures.

Ganguly et al. (2010) compared samples that consisted of students chosen randomly from various business schools in India, USA and Canada. The study revealed that culture at the individual level moderated the relation between website design elements and trust and between trust and intention to purchase online. They also found that in some cases, culture failed to moderate the link between the two variables at the individual level but not at the country level. For example, collectivism lead to differences in the two samples in light of visual design as a trust predictor. However, no moderating effect was found with the inclusion of India. This suggests that culture acted at the individual level but not at the country level and this has a significant implication as it supports the claim that there could be variations in culture.

Regarding different cultures within a country, Alam et al. (2008) hypothesized important difference among different races in Malaysia in their online shopping so that suitable promotional strategy for the vendor to sell their online product or services can be suggested. However, they found no important difference in online shopping among different races (Indian, Chinese, Malay and others) in Malaysia. Based on the result, they recommended that any company wishing to market its product or service online in Malaysia should not develop different marketing strategies based on different races especially with Malaysian consumers.

\subsection{Attitude towards Behavior}

The first construct in theory of planned behavior is attitude towards a target behavior. An attitude is defined as the extent to which an individual has a favorable or unfavorable evaluation or appraisal of the behavior in question (Ajzen, 1991). Theory of planned behavior considers attitude as a function of information or beliefs that are significant to the target behavior. People generally develop perceptions regarding the behavior related to a particular outcome or to some attributes (e.g., the cost to conduct the behavior) that are significant to them. When people believe that behaviors are associated with desirable outcomes, favorable attitudes toward behaviors are developed.

Attitude theory says there is or might be a causal influence of attitude on behavior (attitude $\rightarrow$ behavior) (Assael, 1992). This is one reason for the popularity of the attitude concept in marketing theory and practice. If this hypothetical causal relation really exists, then it is possible to explain and forecast a person's behavior by analyzing his/her attitude. Furthermore, it is possible to use this relation to change a person's behavior by changing his/her attitude.

\subsubsection{Attitude Intentions Research}

The concept attitude is a fundamental construct in social sciences. Social psychologists propose that attitudes guide behavior and often explain it. When attempting to predict and understand human behavior, social psychologists investigate the underlying attitudes as causal indicants of human behavior. As a result, an individual's behavior can be easier understood when their behavior-relevant attitudes are explored.

E-commerce studies have shown a positive effect of attitudes on purchase intentions. Tan and Teo (2000) online survey indicated that attitudes played an important role in controlling intention to Internet banking adoption. Bodmer (2009), in her doctoral dissertation, found that customers' attitudes significantly impacted their behavioral intention. In addition, Jarvenpaa et al. (2000) demonstrated that favorable attitude to e-commerce significantly impacted the consumers' inclination to buy online products. Likewise Lynch et al. (2001) experimental study supported a positive linkage between attitudes toward the websites and intentions to purchase. Their series of experiments in 12 countries showed significant positive effects of attitudes toward online shopping on intentions to purchase.

Information regarding consumer beliefs, opinions and attitudes of a certain object is needed to understand consumer behavior towards the object (Schiffman and Kanuk, 1997). Morris et al. (2002) studied the role of attitudes in behavior prediction and revealed that a positive attitude was an imperative condition for inclination to purchase. Besides, the attitudes of users regarding particular aspects of the Internet determine the cyber-features of the Internet and the cyberbehavior (Hoffman et al., 1999). According to a study by Kimery and McCord (2002), consumers' attitude towards e-retailer purchasing positively impacted their 
intention to purchase from that particular e-retailer. Similarly, Li and Zhang (2002) found that consumer's intention to shop online was positively linked with attitude towards Internet buying and their decision to purchase. In addition, the results of a study conducted by Almoawi (2011) revealed that attitude had an important, positive link with e-commerce adoption.

Theory of planned behavior (Ajzen, 1991) proposes that a person's intention to carry out a behavior increases as his or her attitudes toward the behavior becomes more favorable. Through the process of learning, positive outcomes normally heighten an individual's feelings towards the behavior leading to the outcome achievement. Along the same line, this study posits that customers' favorable attitudes toward shopping online arise from their beliefs about the consequences resulting from shopping with particular websites and their affective responses to those consequences will increase their intentions to shop with particular web merchants. Theoretical and empirical justifications for the link between attitude and intended behaviors can be found in the works of several researchers (Lynch et al., 2001).

\subsection{Definition of E-service Quality}

According to Asubonteng et al. (1996), e -service quality is, the difference between customers' expectations for service performance priorto the service encounter and their perceptions of the service received while Bitner et al. (1990) defined it as the consumers' overall impression of the relative inferiority/superiority of the organization and its services. These definitions vary from person to person but their essence is similar (Khalil, 2011). Ojo (2010) stated that the definition of service quality differs only in their wording but they generally relate to the determination of whether perceived service delivery leads to the meeting, exceeding, or failure to satisfy customer expectations.

Service quality may be defined as the difference between customers' perceptions of the service received and their expectations about service performance prior to the service offering (Asubonteng et al., 1996). If service performance does not meet expectations, people will think that the service quality low. However, when performance goes over expectations, the perception of the service quality is higher (Connolly, 2007). Therefore, customers' expectations are crucial in evaluating service quality. In addition, Asubonteng et al. (1996) found that when service quality increases, intentions to use the service or product and satisfaction increase.
Most practitioners as well as researchers use web service quality and e-service quality synonymously. For instance, Zeithaml (2002) defined e-service quality as the level to which a website uses effective and efficient shopping, purchasing and delivery of goods and services, while Zhang and Prybutok (2005) utilized the same concept to describe quality of website service. Similarly, Santos (2003) defined e-service quality as consumer overall opinions and evaluation regarding the excellent e-service delivery in online market while Colier and Bienstock (2006) provided a description of e-service quality as the user's perceptions of the result of the service delivery as well as their perceptions of service recover in case of service failures.

\subsection{Dimensions of E-service Quality}

Due to the recent growth in e-service quality in the field of e-commerce, the importance of monitoring and measuring e-service quality has provided value to the virtual world. In addition, e-service quality has turn out to be a significant topic in the field of business research. Onset, a clear difference is revealed between traditional service quality and e-service quality as stated by Lee and Lin (2005):

- The absence of sales man in e-services wherein there is no actual business communications between customers and sales representatives like in the traditional service

- The obvious absence of traditional tangible factors as the interaction is conducted in the virtual environment involving some intangible factors. The effective environment involves some real factors

- The self-service of customers in e-service wherein customers generally serve themselves on their own in the purchasing interaction and they control the process of business

There has been ongoing development in the knowledge dealing with quality dimensions of e-service quality (Kim et al., 2006). Most of these studies combined elements of the dimensions of traditional service quality with the dimensions of web-based service quality. According to Gounaris et al. (2005), the eservice quality perception is impacted by varying predictors and several studies have attempted to provide a description of e-service quality in the past years and majority of them have tackled dimensions present in different aspects of customer's interaction in e-shopping. In the present study, some of the important literatures 
that have succeeded in developing and validating measurement criteria for perceived e-service quality are discussed and the most suitable scale is chosen.

E-service quality measurement in online shopping has been receiving increasing attention currently and as a result, many studies have tried to highlight major dimensions of e-service quality linked with online environment. These research works were conducted in different contexts such as e-service, online travel agency, online banking, online retailing, web portal, online public library and online shopping (Table 1). The Table 1 summarizes the studies that identified e-service quality dimensions.

The number of e-service quality studies is increasing and they show varying dimensions of e-service quality. A scale known as SITEQUAL, utilized to measure website quality, is proposed by Yoo and Donthu (2001). It is primarily based on four factors, namely, aesthetic design, processing speed, ease of use and security. Cox and Dale (2001) stated that traditional dimensions of service quality including courtesy, cleanliness, comfort and competence are not compatible for online service quality while dimensions like availability, appearance, credibility, communication, understanding, accessibility are important for the online environment.

Rowley (2006) reported that pioneering study in eservice is still in their beginning and more work is required to extract an exact explanation and measure of e-service quality. He attempted to provide a summary of the service quality dimensions from 29 sources dedicated to e-service quality between 1996 and 2006. These dimensions are listed on the basis of frequency of appearance such as site features comprising design, intuitiveness, ease of use, ease of navigation site aesthetics, appearance, visual appeal, structure, interaction, sensation and ease of ordering (25 sources), security (24), responsiveness (15), reliability (13), accessibility (13), information (10), communication (8), personalization (7), delivery (7), customer support (5) and others (18).

Table 1. Summary of studies on e-service quality dimensions

\begin{tabular}{|c|c|c|}
\hline Author(s) & Dimensions & Context \\
\hline Zeithaml et al. (2000) & $\begin{array}{l}\text { Contact, compensation, responsiveness, privacy, fulfillment, } \\
\text { reliability and efficiency }\end{array}$ & Online retailing \\
\hline Yoo and Douthu (2001) & Security, processing speed, aesthetic design and Ease of use & Online retailing \\
\hline Cox and Dale (2001) & $\begin{array}{l}\text { Availability, understanding, credibility, accessibility, communication } \\
\text { and website appearance }\end{array}$ & Online retailing \\
\hline Yang (2001) & Information, security and website design & Online retailing \\
\hline Wolfinbarger and Gilly (2003) & Customer service, security, reliability and website design & Online shopping sites \\
\hline Zeithaml et al. (2002) & Delivery, responsiveness, security, reliability and communication & E-service \\
\hline Madu and Madu (2002) & $\begin{array}{l}\text { Empathy, assurance, reputation, web store police, service differentiation } \\
\text { and customization, responsiveness, trust, security and system integrity, } \\
\text { serviceability, reliability, aesthetics, structure, features and performance }\end{array}$ & E-service \\
\hline Loiacono et al. (2002) & $\begin{array}{l}\text { Substitutability, business process, integrated communication, } \\
\text { innovativeness, flow, intuitiveness, website design, response time, } \\
\text { trust, interactivity and information }\end{array}$ & Online retailing \\
\hline Surjadaja et al. (2003) & $\begin{array}{l}\text { Customization, delivery, reliability, information, responsiveness, } \\
\text { interaction and security }\end{array}$ & E-service \\
\hline Santos (2003) & $\begin{array}{l}\text { Customer support, incentive, security, communication, reliability, } \\
\text { efficiency, content, structure, linkage, appearance, ease of use }\end{array}$ & E-service \\
\hline Gounaris et al. (2005) & Reputation, responsiveness, trust, information and website design. & Online retailing \\
\hline Parasuraman et al. (2005) & $\begin{array}{l}\text { Contact, compensation, responsiveness, privacy, fulfillment, availability } \\
\text { and efficiency }\end{array}$ & E-service \\
\hline Lee and Lin (2005) & Personalization, trust, responsiveness, reliability and website design & Online retailing \\
\hline Kim et al. (2006) & $\begin{array}{l}\text { Graphic style, information, contact, Compensation, responsiveness, } \\
\text { privacy, system availability, fulfillment and efficiency }\end{array}$ & Online retailing \\
\hline Fassnacht and Koese (2006) & $\begin{array}{l}\text { Emotional benefit, functional benefit, reliability, technical quality, ease } \\
\text { of use, information, attractiveness of selection, layout and graphic quality }\end{array}$ & E-service \\
\hline Sohn and Tadisina (2008) & $\begin{array}{l}\text { Functionality, website content, communication, customized, ease of use, } \\
\text { reliability, speed of delivery and trust }\end{array}$ & Online finance \\
\hline
\end{tabular}


Zeithaml et al., (2000) revealed many website features are based on the perceptual level and separated them into 11 dimensions of e- service quality. These dimensions are described below:

- Reliability-the correct technical functioning of the website and its accurate service offers (delivering of promised stocks, delivering of ordered stock, available items in stock, product information and billing)

- Responsiveness-the timely response and the recourse for help in case of issues or inquiries

- Access-the ability to access the site in a timely manner and to reach the company when necessary

- Flexibility-the varying choices of payment, shipment, buying, searching and return of items

- Ease of navigation-the site functions that help consumers find what they are searching for with ease. In other words, it refers to the system functionality and the user-friendly features

- Efficiency-the simple and easy to use feature of the site, its proper structure and the requirement of minimum information to be entered into by consumers

- Assurance/trust-the customer's confidence in handling the site and the reputation of the site's services and products and its clear and truthful information

- Security/privacy-the extent to which the customer is convinced of the site's safety from intrusion and protection of personal information

- Price knowledge-the level to which the customer determines the total price, shipping price and the relative prices when shopping

- Site aesthetics-site appearance

- Customization/personalization-the easy tailoring of the site to individual customer's preferences, histories and method of shopping

E-S-QUAL is commonly used in online service quality study. Kim et al. (2006) made use of it to measure online e-service quality measure to determine the main factors contributing to clients' satisfaction. The E-S-QUAL may be utilized along with E-RecS-QUAL scale, which measures the quality of recovery service offered by the site. The E-RecS-QUAL scale has the dimensions of responsiveness, compensation and contact to deal with customer issues or inquiries (Mekovec et al., 2007). This method is the basis of the e- services quality evaluation approaches (Cernea et al., 2009). Summary of studies on e-service quality dimensions showed in the following Table 1.

\subsection{Trust}

Several researchers have carried out empirical studies concerning trust in the context of e-commerce. Some of them generally considered trust as trusting the other party (Gefen, 2000). Among the well-known studies is the one carried out by Mayer et al., (1995) who defined trust as the trustor's intention to take risk and suggested the main predictors of trust as the trustor's perceptions regarding the trustee's characteristics. Another well-known study was conducted by McKnight et al. (1998). In their model, trust was considered as comprising trust intention and trusting beliefs specifically in risky and uncertain cases. Pavlou and Gefen (2004) described trust as the perception of the buyer of the suitable situations in place to bring about the process of transaction with online sellers. Sonja (2002), on the other hand, found that trust had a significant role in the increase of electronic business and suggested that some of its serious factors should be examined.

Recent researches have shown that a fundamental lack of trust between most online consumers and businesses is the main reason why many consumers have yet to buy products online or even provide information to web providers (Metehan and Yasemin, 2011). Based on Yoon (2002) study, online trust is not similar to offline trust in three ways. First, there is a substantial distance between the buyer and seller; second, there is no presence of a sales person in online trust and third, the buyer does not have physical contact with the product.

Trust is significant for the success of online consumer purchasing (Jarvenpaa and Tractinsky, 1999). In addition, it was revealed that trusting beliefs affect positively online shopping intentions (Verhagen et al., 2006). Several scholars maintained that minimal consumer's trust in online vendors is an important hindrance to long-term electronic commerce (Crowell, 2001). The trustworthiness perception of online vendors is specifically important in the facilitation of electronic commerce adoption especially when consumers perceive online shopping as riskier than traditional shopping (Metzger, 2006). Several studies (Tan and Sutherland, 2004) indicated that costumer's trust in online purchasing is a critical element that facilitates online businesses success.

\subsubsection{Definition of Trust}

Trust is a relatively old concept in the view of business practitioners. It is a critical construct in buyerseller relation (Morgan and Hunt, 1994). Trust is also an important construct in the context of marketing. A stated 
by Berry and Parasuraman (1991), customers generally buy products after experiencing trust.

The trust concept differs across varying disciplines. Trust is generally defined as (1) a show of confidence between the parties to the exchange or to the relationship (Garbarino and Johnson, 1999); (2) the confidence that no partner to the relation will make use of the other's vulnerability (Dwyer et al., 1987); (3) the confidence on depending on the other party (Moorman et al., 1993); or (4) viewing another party's motives on a positive light in cases involving risky situations (Das and Teng, 1998). Mayer et al., 1995) defined trust as "the willingness of a party to be vulnerable to the actions of another party based on the expectation that the other party will perform a particular action important to the trustor, irrespective of the ability to monitor or control that other party. On the basis of the above conceptualizations, trust can be considered as a trustor's (consumer) inclination to depend on the trustee and to decide on taking an action in a risk laden situation whereby the trustor becomes vulnerable to the trustee (online seller), in the hope of a positive outcome. It is a positive expectation consumers have about online merchants based on their beliefs in the perceived reliability, dependability and confidence in salespersons, information provided on the website, or buying processes (such as credit card transactions) (Fogg and Hsiang, 1999) and are willing to rely on the online merchant. In other words, trust can be regarded as a means to reduce consumers' risks and diminish perceived complexities when engaging in an online transaction. Trust helps consumers to feel secure when engaging in an online business by reducing information complexity as well as lowering the perceived risk of a transaction (Hoffman et al., 1999).

\subsubsection{Dimensions of Trust}

There have been several attempts to examine the dimensional nature of the concept of trust (Dwyer and LaGace, 1986). Literature in marketing indicates varying measures and conceptualizations of trust that are uni-dimensional (Morgan and Hunt, 1994), twodimensional (Kumar et al., 1995) or three-dimensional (Mayer et al., 1995).

Other researchers have conceptualized trust in a global way and considered its many dimensions as its antecedents. For instance, Doney and Cannon's (1997) study initially proposed that trust had a two-dimensional composition (credibility and benevolence). However, their results later showed that trust emerged as uni- dimensional, global concept. By treating trust as a unidimensional construct, Confirmatory Factory Analysis (CFA) procedures indicated that a single dimension measuring supplier firm trust $(\mathrm{a}=0.94)$ and salesperson trust $(\mathrm{a}=0.90)$ exhibited high reliability.

Another study supporting the uni-dimensionality perspective of trust was conducted by Joshi and Stump (1999). In their study of joint action in manufacturersupplier relationships, supplier trust was treated as a unidimensional concept. By comparing the results of measurement models with a series of 10 different alternative measurement models using multi-dimensional trust components, the single-dimension trust scale used in their research had the best measurement properties.

But some researchers defined trust as multidimensional construct i.e., "'a buyer's intentions to accept vulnerability based on his/her beliefs that transactions with a seller will meet his/her confident transaction expectations due to the seller's competence, integrity and benevolence"' (Mayer et al., 1995).

The online trust concept has been studied from various angles and perspectives employing the dimensional concepts (Pavlou et al., 2007). Various models (Lopez-Claros, 2006) have been drawn from extensive research in trust.

In the literature, trust is proposed to have two dimensions: Credibility (competence, ability, integrity, honesty, or reliability) and benevolence (good will trust) (Pavlou, 2002). Pavlou and Chai (2002) revealed that the two different determinants of trust namely credibility and benevolence had different relations with other variables. The concept of credibility comprises both integrity and ability, which describes consumers' expectations of the vendor's behavior during the transaction while benevolence is the former's confidence in the latter's intentions and goodwill of caring (Ring and Van de Ven, 1992). Hwang and Kim (2007) revealed that benevolence is a more complex dimension of online trust and is directly affected by web quality perception and service contents instead of being mediated by affective negative reactions (e.g., anxiety).

\subsubsection{Research on Trust}

Consumers' lack of trust in Internet shopping is one of the critical reasons for their not purchasing online (Metehan and Yasemin, 2011). Online shoppers who have a high level of trust for the site are more likely to complete an electronic transaction (Metehan and Yasemin, 2011). Garbarino and Johnson (1999) studied the role of trust in consumer relationships with nonprofit repertory theater's. They showed that trust mediated between attitudes and future intentions to interact with the firms. 
Gefen (2002) conducted an empirical study to examine the effects of overall online customer trust in the web vendor on shopping intentions among online customers. Trust in this study was referred to as perceptions regarding the ability, integrity and benevolence of the party being trusted. Results showed that the overall trust consumers had on the online vendor maximized their inclination to purchase from the seller online. In a different study, Lynch et al. (2001) investigated the key predictors of consumers' intention to shop online. Results from the experiment showed that trust had a positive effect on buying intention. The results suggested that trust positively led to purchase intention for the case of T-shirts. Alternatively, Hoffman et al. (1999) demonstrated that a low degree of trust generated high purchased risk, high disagreement, high defection vulnerability, less cooperation and less constructive conflict.

\subsection{Risk in Online Shopping}

Perceived risk is defined as the uncertainty consumer's face when they cannot predict the outcome of their decisions to purchase (Schiffman et al., 2007). Perceived risk is considered as the customer's subjective belief regarding the probable negative consequence of their purchase decisions. The risk perceptions of consumers vary from one consumer to another according to factors such as the product category, person and the shopping situation. Perceived risk is also revealed to affect the consumer's likelihood of buying new services or products.

Perceived risk has proven to be an important construct in many consumer behavior research projects. While it was very popular in the 1960's and 1970's, in recent decades research into this construct has waned. However, with increased interest in researching the new e-commerce market space where buyers and sellers are usually faceless and distant, renewed interest into the perceived risk construct should emerge.

The first measurement of perceived risk was developed by Cunningham (1967) and was based on Cox and Rich (1964) two components (uncertainty and danger). Cunningham used two 3-point scales multiplied together to come up with an ordinal scaling of a group of product classes. The two general models of perceived risk involve either the two components of uncertainty and consequences (Cox), or probability of loss and importance of loss (Peter and Tarpey, 1975). The importance of loss has been viewed as a proxy for negative utility (Peter and Ryan, 1976).

\subsubsection{Risk Definition and Dimensions}

Perceived risk has been studied in marketing for over 40 years and appears to be an appropriate construct to understand consumer adoption of e-commerce payment systems. Bauer (1960) proposed the perceived risk concept to the marketing literature following his conceptualization of consumer behavior as risk taking. Bauer reported that, Consumer behavior involves risk in the sense that any action of a consumer will produce consequences which he cannot anticipate with anything approximating certainty and some of which are likely to be unpleasant. Based on Taylor (1974) proposition, since the result of the consumption choice may only be revealed in the future, the consumer is faced with uncertainty.

Perceived risk has been defined as an influence on choice decisions and may be defined as the expectation of losses associated with purchase and acts as an inhibitor to purchase behavior (Peter and Ryan, 1976). On the other hand, Bauer (1960) defined perceived risk as a combination of uncertainty plus seriousness of outcome involved-associated with each category of product. Perceived risk is also defined as an uncertainty function relating to the outcome of the decision (Jacoby and Kaplan, 1972).

In the context of online shopping, Chellappa et al. (2005) defined perceived risk as the uncertainty that customers experience when they cannot predict the outcome of their purchase decisions. Also Hassan and Kasiran (2006) defined perceived risk in online shopping as the expectations of any loss or any negative consequences as a result of online shopping. Because the Internet is described as a global and a virtual channel of selling and buying product and services, the seller cannot be felt in a physical sense and this creates an uncertainty perception in online transactions and therefore, perceived risk is important in online purchasing. Based on Jarvenpaa and Tractinsky (1999), there is no assurance that the consumer will obtain the goods that he/she sees in the Internet. In case of technical problems in the process of transaction, the seller is not the one to bear the cost.

Pavlou (2003) defined perceived risk as the distant and impersonal nature of the online environment and the implicit uncertainty of using a global open infrastructure for transactions have rendered risk an inevitable element of e-commerce. It is complicated to measure it as an objective fact. Hence, most literature emphasizes the concept of individually perceived risk and defined it as consumers' subjective belief in which a loss was caused by the outcome they pursued (Pavlou and Gefen, 
2004). In a study done by Forsythe and Shi (2003), they indicated that perceived risk of online shopping mainly came from the loss that consumers expected to have in the process of an electronic transaction. Generally, consumers thought that the perceived risk was caused by the perception that the Internet was not a secure territory or the degree of negative influence possibly resulted from a result (Grazioli and Jarvenpaa, 2000).

\subsubsection{Online Risk Studies}

Purchasing is considered a risky business specifically in the online purchasing environment. Following the background of perceived risk in the literature of consumer behavior, many studies have tried to define the perceived risk concept and how it affects consumer behavior. Several research works claim that perceived risk in electronic commerce has a significant impact on attitude towards online shopping (Shih, 2004), intention to shop through the Internet (Pavlou, 2003) and Internet purchasing behavior (Bodmer, 2009).

The main issues of online purchasing are privacy of personal information and safety of online payments (Cunningham et al., 2005). Privacy problem has been shown to have a negative relation with online shopping behavior and it denies customers from shopping online (Doolin et al., 2005). But lower degrees of privacy risk do not necessarily translate to a great inclination to shop online (Amoroso and Hunsinger, 2008), as this also has something to do with lack of social interaction in online shopping experience (Doolin et al., 2005) and the lack of opportunity to inspect and see the products; both of these aspects makes the shopper vulnerable to fraud compared to a physical merchant in a store. Customers also revealed their wariness over return of products and delivery they had purchased via the Internet (Jarvenpaa and Todd, 1997). Another risk is phishing where customers are fraudulently made to think they are interacting with an honest dealer when in actuality, they are being fooled to providing their private information to a corrupt party.

Kim and Lim (2001) investigated effects of perceived risk on purchasing decision in online shopping. The author also examined various strategies to reduce perceived risk. The results indicated that perceived risk in online shopping was greater than the perceived risk in in-store shopping. In addition, positive online shopping experience reduced consumers' perceived risk. Kim also found that higher perceived risk negatively affected online purchasing intentions. The results also indicated that relationships between perceived risk and purchasing intentions that existed in mail-order shopping and instore shopping existed in online shopping.

\section{RELATIONSHIP AMONG E-SERVICE QUALITY, CULTURE, ATTITUDE, TRUST, RISK OF ONLINE SHOPPING}

\subsection{Relationship between E-service Quality and Culture}

Starting from $1990 \mathrm{~s}$, a number of research works have emerged on the effect of culture and service quality. For instance Anderson and Fornell (1993) recommended the link between culture and service quality to be examined. Malhotra et al. (1994) also conceptually speculated the possible links. Among the first to investigate the effect of culture on service quality are research works by Donthu and Yoo (1998) and Furrer et al. (2000). In recent years, studies began to elaborate more on the relationship between culture and service quality (Ueltschy et al., 2009).

However, research concerning electronic service quality has just begun to gain ground and the main issue related to the studies is the factorial structure of the constructs and measurement (Wolfinbarger and Gilly, 2003). Nevertheless, although research on these issues has shown significant development, their cross-national considerations are few and far between (Vlachos and Vrechopoulos, 2008). This gap has been acknowledged by some researchers such as Wolfinbarger and Gilly (2003) when they called for more researches to address electronic service quality on a global scale. Furthermore, debates concerning service quality in literature discuss the generalizability of service quality dimensions in various countries. For example, Tsikriktsis (2002) conducted a research of the stability of electronic service quality dimensionality in different countries. It was revealed that every country has its own unique quality dimensions (Zhao et al., 2002), which have different degrees of importance (Feinburg et al., 1995).

Regardless of the fact that the Internet has assisted in the service globalization, only a few studies tackled the relationship and impact of cultural dimensions and characteristics on online perceived service quality. While the exploratory study carried out by Marcus and Gould, (2000) only compared between the features of the website and Internet portals design in different cultures. They also highlighted the effect of the perceptions of cultural differences upon website design and features, but the specific characteristics of users based on their perceived e-service quality are yet to be examined (Sigala and Sakellaridis, 2004). 
Sigala and Sakellaridis (2004) found that only three of the cultural dimensions proposed by Hofstede, namely, masculinity, power distance and long-term orientation, affected the perception of specific WEBQUAL dimensions. Donthu and Yoo (1988) found that cultural elements had the greatest impact on service quality in traditional stores when the service included a high degree of customer-provider interaction, while Tsikriktsis (2002) showed that culture affected website service quality expectations less than it affected traditional service quality.

Vlachos and Vrechopoulos (2008) found participants in Japan, Hong Kong and Korea looked at the construct of service quality in the same way. However, they did not consider the impact of cultural dimensions on electronic service quality perception dimensions. Within the context of this study, countries were considered as cultural characteristics proxies (Kim et al., 2004). Though they believed that the mobile e-service quality dimensions are distinct in the three Asian countries discussed, they called for more research investigations that could definitely link the effect of culture on the service quality dimensions.

In the context of Malaysia, Khalid Ali et al. (2008) proposed a new service quality dimension that is related to the "Halal" issue. "Halal" is an Arabic word meaning permissible from a religious view and it applies to all food products, food ingredients, meat products and food contact materials in the grocery stores. Despite of the fact that $60 \%$ of the Malaysian populations are Muslims, several stores are run by foreign individuals or by non-Muslim Malaysians. In fact, the Halal dimension was proposed as a dimension that measures customer service quality in Islamic banking (Othman and Owen, 2001) and insurance firms (Tahir and Ismail, 2004).

Even though the concept of service quality has been investigated in the information systems context (Sigala, 2004), research dealing with the effect of cultural differences upon e-service quality are still few and far between. According to a study conducted by Marcus and Gould (2000), cultural differences do have an effect on website design and features. However, through Hofstede (1994) dimensions of culture comprising individualism, power distance, uncertainty avoidance, masculinity and long-term orientation, many studies reviewed by Furrer et al. (2000) supported the impact of five cultural dimensions upon the importance consumers place on and their expectations of service quality.

\subsection{Relationship between Trust and E-service Quality}

Trust has been considered as a determinant in ecommerce research (Grabner-Krauter and Kaluscha, 2003). However, a few have actually linked trust with electronic service quality (Sahadev and Purani, 2008). On the basis of Zeithaml et al., (2002) study, service quality in online shopping is a significant strategy to achieve success, even more than low prices and web presence. Alsajjan et al. (2006) found that e-service quality is a prominent variable in literature dedicated to trust. Harris and Goode (2004) revealed a correlation between e-service quality and determinants of trust. Service quality reflects the idea of customers comparing their expectations concerning the performance of service (Gronroos, 1984).

Harris and Goode (2004) revealed that there is a link between electronic service quality and trust. They indicated that customer's judgment was mainly based on the perception of the retailer's performance (trust, reputation, size, service quality) and the website interaction quality (graphic style, navigation, ease of use and informativeness). Zhang and Tang (2006) also showed that trust was a crucial dimension of the eservice quality perception in web transactions.

The theoretical relationship between service quality and trust has been advocated by several research studies in different ways, for example: Chuang and Fan (2011) reported that service quality determines trust and that a service quality delivered by e-retailer that satisfies customer's expectations encourages trust belief. Zhou et al. (2010) also revealed that service quality significantly impacts trust. Moreover, Wakefield et al. (2004) stated that Quality of service can develop the initial trust of the consumer, but the absence of service quality may prevent the consumers from being satisfied and from trusting the service provider. In another study conducted by Martin and Camarero (2008), they found that service quality also influences trust; it only does so indirectly through satisfaction.

The significance of online service quality is reflected by studies linking service quality with trust. Many attempts have been made to incorporate measure of trust perceptions into the overall e-service quality (Zeithaml et al., 2000). Previous researches have shown a direct relation between quality and trust (Chen et al., 2002). Accordingly, Hennig-Thurau and Klee (1997) reported that a perception of quality at all levels produced online trust. Service quality was found to 
have a positive impact on trust in Internet stores (McKnight et al., 2002). On the contrary, Chen et al. (2002) did not find service quality to be linked with trust on online transactions.

Customer perception of the quality of a company's service affects trust in online purchasing (Kim and Tadisina, 2007). Such perception is postulated to be the most important factor in the continuance of trust and in building a strong relationship between e-retailer and customer (Mao, 2010). This is supported by Anderson and Fornell (1994) study where they revealed that greater levels of quality of service might lead to greater levels of satisfaction, which will in turn result in the consumer's understanding of the company and the positive experience. Moreover, perceived service quality was found to play the main role in the determination of customer trust in online shopping (Kim et al., 2004). Websites that are considered well quality and easy to use have more possibility of building great levels of consumer trust (Wakefield et al., 2004).

Findings regarding relational benefits revealed that perceptions of service quality had a positive effect on relational outcomes including trust (Yen and Gwinner, 2003). Hence, it is imperative for businesses to take into account that e-service quality is an important factor in developing customer trust and relationship (Lee and Lin, 2005). Reichheld and Schefter (2000) proposed that positive experiences of service quality boosts trust and therefore a positive direct effect of quality on trust could be predicted.

Service quality elements are predicted to influence electronic trust directly (Gronroos et al., 2000) as they represent elements of trust that relay the system to customers and the trustworthiness of the site (Corritore et al., 2003). After reviewing research on online trust, Grabner-Krauter and Kalusha (2003) proposed electronic service quality constructs to include repurchase intentions as trusting intentions and trusting beliefs. Furthermore, Corritore et al. (2003) proposed that websites as objects to be trusted and claimed that design elements and the navigational architecture impact trust directly. Similarly, in the research done by Davis et al. (2000) on e-service quality retailing products, they revealed that trust on e-vendors was imperative.

A positive and direct relation between trust and service quality was found by two studies conducted by Harris and Goode (2004). In their first study on book.com, service quality was revealed to be an important antecedent of trust. In the second study on airlines.com, the link between service quality and trust was not as strong as in the first study despite being significant. Using Linear Structural Relations (LISREL), Shrout and Bolger (2002) found that eservice quality did not have a significant direct effect on online trust; rather the link was indirect via perceived value and customer satisfaction.

\subsection{Relationship between Trust and Risk}

In the present section, the relation between trust and risk is discussed. Trust is defined as the willingness to expose one's self to the actions of the third party on the basis of the expectation that the other party will behave in a manner predetermined (Lowry et al. 2008). Risk, on the other hand, is the doubt that customers often experience when they fail to predict the outcome of their purchase decisions (Chellappa et al., 2005).

It is believed that electronic dealings are offered to customers with a lot of uncertainty (Grabner-Krauter and Kalusha, 2003). Purchasing online for example is considered a risky process because of the lack of contact between customers and firms, i.e., through physical store or the sales representatives (Reichheld and Schefter, 2000). Besides, customers have to send important information about them such as the number of their credit card in order to complete the electronic transaction. The absence of face-to-face interaction also implicates that online trust is important and based on capabilities of the retailer and customers' judgments of reliability (McAllister, 1995).

Kehoe (2002) examined the impact of risk and trust on the behavior of online and offline shoppers. Results indicated that perceived risk in online shopping was significantly higher than perceived risk in a traditional shopping or other remote types of shopping such as mailorder, telephone, etc. In addition, consumers' knowledge of Internet security-related technologies was negatively related with perceived risk in online shopping.

Trust is critical for the success of online shopping (Jarvenpaa and Tractinsky, 1999). It has been demonstrated that trusting beliefs positively influence online consumers' purchase intentions (Verhagen et al., 2006). Moreover, lack of consumer's trust in online vendors has been highlighted by a number of researchers as a serious barrier to the long-term diffusion of electronic commerce (Crowell, 2001). Perceived trustworthiness of online stores is relevant as an enabler of electronic commerce adoption because consumers continue to perceive online purchasing as riskier than traditional shopping (Metzger, 2006). Several researchers (Doolin et al., 2005) suggested that consumer's trust in Internet shopping is a vital ingredient that contributes to the successful online businesses. 
People frequently have a general perception that performing economic transactions over the Internet and with specific online entities is somewhat risky (Lowry et al., 2008). This risk perception necessitates the establishment of trust so that buyers will engage in online transactions. Moreover, risk perception has been cited as one of the largest impediments to realizing the full economic potential of the Internet (Lim et al., 2006). Risk, or the probability of adverse outcomes, is the antithesis of trust, the willingness to accept negative outcomes. Thus, perceived risk is reduced when the online vendor is perceived to be trustworthy (McKnight et al., 1998). This adverse relationship between risk and trust in the online context is supported by many other studies. For example, Jarvenpaa and Tractinksy (1999) were the first to report that trust and perceived risk are negatively related in ecommerce transactions. Similar findings were also reported elsewhere (Malhotra et al., 2004).

Study conducted by Pavlou (2003) found that the impact of risk perception on trust in e-commerce was not significant; implicating that risk may not be a causal antecedent of trust. Instead, trust is an important predictor of risk perception, suggesting that the directionality of the causal link starts from trust to risk perception. Drawing upon the practical results for trust and risk relationship, it may be concluded that trust in online shopping also acts indirectly on intention to purchase online via the mediating impact of risk perception, on which it has a direct impact. Pavlou also stressed that future study should examine the complicated relationship between trust and perceived risk to reach clearer conclusions.

The moderating link between trust and risk perception indicates that "trust on behavior is different when the level of risk is low versus when the level of risk is high" (Gefen et al., 2003). When the risk is high, trust is triggered. On the contrary, when the risk is low, trust in turn does not emerge. They found the moderating link between these constructs. They reported that perceived risk and the trustor's tendency to trust are mirror images. As a result, high perceived risk includes low trust and vice versa. Grazioli and Wang (2001) examined the moderating link in an electronic trust setting. However, they found different results and their data did not support it.

Threshold model proposes that if the level of trust exceeds the threshold of perceived risks, then the trustor will involve in a risky relationship (Gefen et al., 2003). This proposition is based on Mayer et al. (1995) model. Mayer et al. (1995) stated that one does not need to risk anything in order to trust; however, one must take a risk in order to engage in trusting action). They stressed that willingness is to assume risk, whereas trusting behavior is assuming risk. As a result, trust will lead to risk taking.

San Martin and Camarero (2009) found that only a few researches had studied the moderating impact of risk perception in an online shopping environment. Hence, the moderating role of risk perception related to online shopping is an important topic that has not received enough consideration in the literature. Some researchers have studied the moderating effect of risk perception on the link between trust and shopping behavior or intention (Büttner and Göritz, 2008), on the effect of brand image or reputation on the evaluation of a supplier or a product (Gurhan-Canli and Batra, 2004), on the impact of satisfaction on online trust (San Martin and Camarero, 2009), on the predictor of trust (Martin and Camarero, 2009), or on some links of the Technology Acceptance Model (TAM) (Featherman and Fuller, 2002). San Martin and Camarero (2009) reported that "Since the results partly corroborate the theoretical assumptions, it is necessary to keep working in this line and increase the number of papers using perceived risk as a moderating variable.

Different results were found by Büttner and Göritz (2008). They examined the moderating impact of risk perception on the link between perceived trustworthiness and intention to shop online. The moderation effect was tested by employing the moderation procedure suggested by Baron and Kenny (1986). They revealed no significant impact of the perceived honesty and risks perception interaction. Hence, risks perception had no moderating impact on the link between perceived honesty and intention.

\subsection{Relationship between Trust and Attitude}

Nunkoo et al., (2013) studied online purchase behavior of online travelers. They showed that trust had direct and positive effect on attitude. They explained that trust in a travel website and tourism enables favorable attitude toward buying from these sites since the website is perceived to be reliable and that no harmful consequences will happen if customers carry out online purchasing of travel services and products.

Trust and attitude model has been developed in an attempt to explore acceptance of online shopping (Gefen et al., 2003). The model integrates use of online system with both ease of use and usefulness and trust in e-vendors. Findings revealed that these variables were effective predictors of behavior intention to use online shopping (Gefen et al., 2003). 
Other studies dedicated to online shopping and ecommerce in light of trust revealed that trust had varying impacts on customer intention to shop online via websites, perceived usefulness, or intention to return. For instance, Chiu et al. (2009) found that trust significantly impacted perceived usefulness and repurchase intention of shopping online. In addition, $\mathrm{Wu}$ and Chen (2005), found that trust significantly impacts subjective norm, perceived behavioral control and attitude in a way that perceived ease of use, perceived usefulness and trust had a significant impact on attitude. Similarly, Bodmer (2009) examined the relationship between trust and attitude toward online shopping. He found that trust was a significant antecedent of attitude toward shopping online. Majority of studies revealed that trust plays a key role in the determination of customers' actions. Based on empirical research, trust increases a customer's attitude to purchase product from a company (Nunkoo et al., 2013) and a customer's return intention to the company (Doney and Cannon, 1997). Karjaluoto et al., 2002) showed a positive relationship between trust in online store, perceived usefulness, perceived ease of use and attitude toward online shopping. They also found a negative relationship between perceived risk and attitude towards shopping online. The relation between trust and online consumer attitudes is also supported by Hassanein and Head (2007).

\section{CONCLUSION}

The aim of the study was to explain the factors that affect attitude of consumers towards Internet shopping in Malaysia and Saudi Arabia and how they affect purchase attitude. The findings revealed that service quality was relatively significant in its impact on consumer trust in online shopping, proving the proposed positive direct impact of perceived service quality upon customer trust. However, perceived risk was revealed to be linked with consumer trust towards online shopping, contrary to the proposed hypothesis. According to the results, trust in online retailer was positively associated with the attitude of consumers to online shopping. Therefore, marketers and managers should take into close consideration the requirements of trust development in online retailing. Finally, trust based on e-service quality is considered as the most suitable environment for developing favorable consumer attitude towards online shopping.

The present study revealed that the proposed relationship between e-service quality and consumer trust was statistically significant. The correlation coefficient of the effect of perceived service quality and consumer trust was high, suggesting that e-service quality strongly and positively affected consumer trust in Internet shopping. People who are likely to attach great importance to service quality tend to show trust in online shopping. Such finding is consistent with prior findings concerning the positive relationship between e-service quality and consumer trust. However, the finding is inconsistent with previous studies that showed no relationship between e-service quality and consumer trust.

The theoretical relationship between service quality and trust has been advocated by several research studies in different ways. For example, Chuang and Fan (2011) found that service quality determined trust and that service quality delivered by e-retailer that satisfied customer's expectations encouraged trust belief. In addition, quality of service was expected to affect customer trust in cases where the service provider has been associated with the customer for a significant time. However, they revealed that not all service quality dimensions reflected the same contribution to trust.

\section{ACKNOWLEDGMENT}

The researchers are thankful to Dr. Faridahwati Mohammad Shamsudin and Dr. Azahari Ramli for their constant help and motivation. They are also thankful to Dr. Sulaiman Althuaib for his continuous support during the data collection process.

\section{REFERENCES}

Ajzen, I., 1991. The theory of planned behavior. Organiz. Behav. Human Decis. Processes, 50: 179-211. DOI: 10.1016/0749-5978(91)90020-T

Alam, S.S., Z. Bakar, H.B. Ismail and M.N. Ahsan, 2008. Young consumers online shopping an empirical study. J. Internet Bus., 5: 81-98.

Almoawi, A.R., 2011. E-commerce adoption among small and medium enterprises in Saudi Arabia. PhD Thesis, University Utara Malaysia.

Alsajjan, A., B. Bander and C. Dennis, 2006. The impact of trust on acceptance of online banking. Proceedings of the European Association of Education and Research in Commercial Distribution, Jun. 27-30, Brunel University, West London.

Amoroso, D.L. and D.S. Hunsinger, 2008. Analysis of the factors that influence online purchasing. 
Anderson, E.W. and C. Fornell, 1994. A Customer Satisfaction Research Prospectus. In: Service Quality: New Directions in Theory and Practice, Rust, R.T. and R.L. Oliver (Eds.), Sage Publications, Thousand Oaks, CA, ISBN-10: 0803949197, pp: 239-266.

Anderson, E.W. and M. Sullivan, 1993. The antecedents and consequences of customer satisfaction for firms. Market. Sci., 12: 1250-143. DOI: 10.1287/mksc.12.2.125

Assael, H., 1992. Consumer Behavior and Marketing Action. 4th Edn., Kent Publishing Company, Boston, MA., ISBN-10: 0534925529, pp: 748.

Asubonteng, P., K.J. McCleary and J.E. Swan, 1996. SERVQUAL revisited: A critical review of service quality. J. Services Market., 10: 62-81. DOI: 10.1108/08876049610148602

Baron, R.M. and D. A. Kenny, 1986. The moderatormediator variable distinction in social psychological research: Conceptual, strategic and statistical considerations. J. Personalityand Soc. Psychol., 51: 1173-1182. DOI: 10.1037/0022-3514.51.6.1173

Bauer, R. A. 1960. Consumer behavior as risk taking. American Marketing Association.

Bearden, W.O., M.R. Bruce and J. Nevins, 2006. A measure of long-term orientation: Development and validation. J. Acad. Market. Sci., 34: 456-467. DOI: 10.1177/0092070306286706

Berry, L.L. and A. Parasuraman, 1991. Marketing Services: Competing through Quality. 1st Edn., The Free Press, New York.

Bitner, M.J., B.H. Booms and M.S. Tetreault, 1990. The service encounter: Diagnosing favorable and unfavorable incidents. J. Market., 71-84. DOI: $10.2307 / 1252174$

Bodmer, J.W., 2009. A Cross Cultural Comparison of American and Swiss Female Perceptions of Trust on Internet Purchase Behaviors, Dissertation. 1st Edn., Nova Southeastern University, ISBN10: 1109119356, pp: 206.

Büttner, O.B. and A.S. Göritz, 2008. Perceived trustworthiness of online shops. J. Consumer Behav., 7: 35-50. DOI: 10.1002/cb.235

Cernea, S.O., J. Sîrbu and N. Marginean, 2009. Determination of users' satisfaction level regarding the quality of e-services provided by "bogdan-vodă" university. Annales Universitatis Apulensis Series Oeconomica, 11: 652-661.
Chellappa, R., A.K. Roy-Chowdhury and S.K. Zhou, 2005. Recognition of Humans and their Activities Using Video. In: Synthesis Lectures on Image, Video and Multimedia Processing, Wang, Z. and A. Bovik (Eds.)., Morgan and Claypool Publishers ISBN-10: 1598290223, pp: 1-173.

Chen, L.D., M.L. Gillenson and D.L. Sherrell, 2002. Enticing online consumers: An extended technology acceptance perspective. Inform. Manage., 39: 705719. DOI: 10.1016/S0378-7206(01)00127-6

Chiu, C.M., C.C. Chang, H.L. Cheng and Y.H. Fang, 2009. Determinants of customer repurchase intention in online shopping. Online Inform. Rev., 33: 761-84. DOI: 10.1108/14684520910985710

Chuang, H.M. and C.J. Fan, 2011. The mediating role of trust in the relationship between e-retailer quality and customer intention of online shopping. African J. Bus. Manage., 5: 9522-9529. DOI: 11.5897/AJBM11,

Colier, J.E. and C.C. Bienstock, 2006. Measuring service quality in e-retailing. J. Service Res., 8: 260-75. DOI: $10.1177 / 1094670505278867$

Connolly, R., 2007. Factors influencing Irish consumers' trust in internet shopping. Electronic Commerce Res. Applic., 2: 203-215. DOI: 10.1108/01409170810865154

Corritore, C.L., B. Kracher and S. Wiedenbeck, 2003. On-line trust: Concepts, evolving themes, a model. Int. J. Human, 58: 737-758. DOI: 10.1016/S10715819(03)00041-7

Cox, D.F. and S.U. Rich, 1964. Perceived risk and consumer decision-making: The case of telephone shopping. J. Market. Res., 1: 32-39. DOI: $10.2307 / 3150375$

Cox, J. and B. Dale, 2001. Service quality and e-commerce: An exploratory analysis. Manag. Service Q., 11: 121-131. DOI: 10.1108/09604520110387257

Crowell, W., 2001. Trust, the e-commerce difference. Credit Card Manage., 14: 80-80.

Cunningham, L., J. Gerlach and M. Harper, 2005. Perceived risk and e-banking services: An analysis from the perspective of the consumer. J. Financial Services Market., 10: 165-178. DOI: 10.1057/palgrave.fsm.4770183

Cunningham, S.M., 1967. The Major Dimensions of Perceived Risk. In: Risk Taking and Information Handling in Consumer Behavior, Cox, D.F.E. (Ed.), Division of Research, Graduate School of Business Administration, Boston, MA., pp: 82-108. 
Das, T.K. and B. Teng, 1998. Between trust and control: Developing confidence in partner cooperation in alliances. Acad. Manage. Rev., 23: 491-512. DOI: 10.5465/AMR.1998.926623

Davis, R., M. Buchanan-Oliver and R. J. Brodie, 2000. Retail service branding in electronic-commerce environments. J. Service Res., 3: 178-86. DOI: $10.1177 / 109467050032006$

Doney, P. and J. Cannon, 1997. An examination of the nature of trust in buyer-seller relationships. J. Market., 61: 35-51. DOI: 10.2307/1251829

Donthu, N. and B. Yoo, 1998. Cultural influences on service quality expectations. J. Service Res., 1: 178186. DOI: 10.1177/109467059800100207

Doolin, B., S. Dillon, F. Thompson and J.L. Corner, 2005. Perceived risk, the internet shopping experience and online purchasing behavior: A New Zealand perspective. J. Global Informa. Manage., 13: 66-88. DOI: 10.4018/jgim.2005040104

Douglas, S. and S. Craig, 1997. The changing dynamic of consumer behavior: Implications for crosscultural research. Int. J. Res. Market., 14: 379-395. DOI: $10.1016 / \mathrm{S} 0167-8116(97) 00026-8$

Dwyer, F.R., nd R.R. LaGace, 1986. On the nature and role of buyer-seller trust. Proceedings of the AMA Summer Educators Conference, (SEC' 86), Chicago: American Marketing Association, pp: 40-45.

Dwyer, F., P. Schurr and O. Soh, 1987. Developing buyer-seller relationships. J. Market., 51: 11-27. DOIL10.2307/1251126

Fassnacht, M. and I. Kose, 2006. Quality of electronic services: Conceptualizing and testing a hierarchical model. J. Service Res., 9: 19-31. DOI: 10.1177/1094670506289531

Featherman, M. and M. Fuller, 2002. Applying TAM to e-services adoption: the moderating role of perceived risk. Proceedings of the 36th Hawaii International Conference on System Sciences, (CSS' 02), IEEE, Hawaii, pp: 1-11.

Feinburg, R.A., K. Ruyter, C. Trappey and T.Z. Lee, 1995. Consumer-defined service quality in international retailing. Total Q. Manage., 6: 61-67. DOI: 10.1080/09544129550035594

Fogg, B.J. and T. Hsiang, 1999. The elements of computer credibility. Proceedings of the SIGCHI Conference on Human Factors in Computing Systems, May 15-20, ACM New York, pp: 80-87. DOI: $10.1145 / 302979.303001$
Forsythe, S.M. and B. Shi, 2003. Consumer patronage and risk perceptions in internet shopping. J. Bus. Res., 56: 867-875. DOI: 10.1016/S01482963(01)00273-9

Furrer, O., B.S.C. Liu and D. Sudharshan, 2000. The relationships between culture and service quality perceptions: Basis for cross-cultural market segmentation and resource allocation. J. Service Res., 2: 355-371. DOI: $10.1177 / 109467050024004$

Ganguly, B., S.B. Dash, D. Cyr and M. Head, 2010. The effects of website design on purchase intention in online shopping: The mediating role of trust and the moderating role of culture. Int. J. Electronic Bus., 8: 302-330. DOI: 10.1504/IJEB.2010.035289

Garbarino, E. and M. Johnson, 1999. The different roles of satisfaction, trust and commitment in customer relationships. J. Market., 63: 70-87. DOI: $10.2307 / 1251946$

Geertz, C., 1973. The Interpretation of Cultures. 1st Edn., Basic Books, New York, ISBN-10: 0465097197, pp: 470.

Gefen, D., 2000. E-Commerce: The role of familiarity and trust. Omega, 28: 725-737. DOI: 10.1016/S0305-0483(00)00021-9

Gefen, D., 2002. Reflections on the dimensions of trust and trustworthiness among online consumers. ACM SIGMIS Database, 33: 38-53. DOI: $10.1145 / 569905.569910$

Gefen, D., V.S. Rao and N. Tractinsky, 2003. The conceptualization of trust, risk and their electronic commerce: The need for clarifications. Proceedings of the 36th Hawaii International Conference on System Sciences, Jan. 6-9, IEEE Xplore Press, DOI: 10.1109/HICSS.2003.1174442

Gounaris, S., S. Dimitriadis and V. Stathakopoulos, 2005. Antecedents of perceived quality in the context of internet retail stores. J. Market. Manage., 21: 669-700. DOI: $10.1362 / 026725705774538390$

Grabner-Krauter, S. and E. A. Kaluscha, 2003. Empirical research in on-line trust: A review and critical assessment. Int. J. Human-Comput. Stud., 58: 783812. DOI: 10.1016/S1071-5819(03)00043-0

Grazioli, S. and S. Jarvenpaa, 2000. Perils of internet fraud: An empirical investigation of deception and trust with experienced internet consumers. IEEE Trans. Syst. Man Cybernet.. 30: 395-410. DOI: $10.1109 / 3468.852434$ 
Grazioli, S. and A. Wang, 2001. Looking without seeing: Understanding unsophisticated consumers' success and failure to detect internet deception. Proceedings of the 22nd International Conference on Information Systems, (CIS' 01), New Orleans, pp; 193-204.

Groeschl, S. and L. Doherty, 2000. Conceptualizing culture. Cross Cult. Manage., 7: 12-17.

Gronroos, C., 1984. A service quality model and its marketing implications. Eur. J. Market., 18: 3644. DOI: 10.1108/EUM0000000004784

Gronroos, C., F. Heinonen, K. Isoniemi and M. Lindholm, 2000. The NetOffer model: A case example from the virtual marketspace. Manage. Decision, 38: 243-252. DOI: $10.1108 / 00251740010326252$

Gurhan-Canli, Z. and R. Batra, 2004. When corporate image affects product evaluations: The moderating role of perceived risk. J. Market. Res., 197-205. DOI: 10.1509/jmkr.41.2.197.28667

Harris, L.C. and M.M.H. Goode, 2004. The four levels of loyalty and the pivotal role of trust: A study of online service dynamics. J. Retail. 80: 139-158. DOI: $10.1016 /$ j.jretai.2004.04.002

Hassan, S. and M.K. Kasiran, 2006. Compliance of X. 509 certification standard in the implementation of third party certification in Malaysian Ecommerce websites. Commun. IBIMA, 5: 42-49.

Hassanein, K. and M. Head, 2007. Manipulating perceived social presence through the web interface and its impact on attitude towards online shopping. Int. J. Human, 65: 689-708. DOI: 10.1016/j.ijhcs.2006.11.018

Hennig-Thurau, T. and A. Klee, 1997. The impact of customer satisfaction and relationship quality on customer retention: A critical reassessment and model development. Psychol. Market., 14: 737$764 . \quad$ DOI: $10.1002 /($ SICI) $1520-$ 6793(199712)14:8<737::AID-MAR2>3.0.CO;2-F

Herskovitz, M.J., 1955. Cultural Anthropology. 1st Edn., Knopf, New York.

Hoffman, D.L., T.P. Novak and M. Peralta, 1999. Building consumer trust online. Commun. ACM, 42: 80-85. DOI: 10.1145/299157.299175

Hofstede, G., 1980. Culture's Consequences: International Differences in Work-Related Values. 1st Edn., Sage Publications, Beverly Hills, ISBN-10: 080391444X, pp: 328.
Hofstede, G., 1984. Culture's Consequences: International Differences in Work-Related Values, abridged edition. Sage, London, pp: 327.

Hofstede, G., 1994. Cultures and Organizations: Software of the Mind. 1st Edn., McGraw-Hill, London.

Hofstede, G., 2001. Cultural Consequence. 2nd Edn., Sage Publicaations, Thousand Oaks.

Hofstede, G. and M. Bond, 1988. The confucius connection: From cultural roots to economic growth. Organiz. Dynam., 16: 4-21. DOI: 10.1016/00902616(88)90009-5

Hwang, Y. and D.J. Kim, 2007. Customer self-service systems: the effects of perceived web quality with service contents on enjoyment, anxiety and e-trust. Decision Support Syst., 43: 746-760. DOI: 10.1016/j.dss.2006.12.008

Jacoby, J. and L.B. Kaplan, 1972. The components of perceived risk. Proceedings of the Third Annual Conference of the Association for Consumer Research, (ACR' 72), Association for Consumer Research, Chicago, pp: 382-393.

Jarvenpaa, S.L. and P.A. Todd, 1997. Consumer reactions to electronic shopping on the World Wide Web. J. Electronic Commerce, 1: 59-88.

Jarvenpaa, S.L., N. Tractinsky and M. Vitale, 2000. Consumer trust in an Internet store. Inform. Technol. Manage., 1: 45-71. DOI: 10.1023/A:1019104520776

Jarvenpaa, S.L. and N. Tractinsky, 1999. Consumer trust in an internet store: A cross-cultural validation. J. Comput., 5: 1-35. DOI: 10.1111/j.10836101.1999.tb00337.x

Joshi, A.W. and R.L. Stump, 1999. The contingent effect of specific asset investments on joint action in manufacturer-supplier relationships: An empirical test of the moderating role of reciprocal asset investments, uncertainty and trust. J. Acad. Market. Sci., 27: 291-305. OI: 10.1177/0092070399273001

Karjaluoto, H., M. Mattila and T. Pento, 2002. Factors underlying attitude formation towards online banking in Finland. Int. J. Bank Market., 20: 261272. DOI: $10.1108 / 02652320210446724$

Kehoe, M. 2002. The role of perceived risk and consumer trust in relation to online shopping and security. Phd Thesis, Florida State University, Florida.

Khalid Ali, K., R. Salleh, S.K. Johl, S. Molek and F. W. Lai et al., 2008. Business Management-A Malaysian Perspective. Oxford Fajar Sdn. Bhd under license from Oxford University Press. 
Khalil, K.M., 2011. Online service quality and customer satisfaction: A case study of Bank Islam Malaysia Berhad. Munich Personal RePEc Archive.

Kim, E. and S. Tadisina, 2007. A model of customers' trust in e-businesses: micro-level inter-party trust formation. J. Comput. Inform. Syst., 48: 88-104.

Kim, H.W., Y. Xu and J. Koh, 2004. A comparison of online trust building factors between potential customers and repeat customers. J. Assoc. Inform. Syst., 5: 392-420.

Kim, M., J.H. Kim and S. Lennon, 2006. Online service attributes available on apparel retail web sites: An E-S-QUAL approach. Manag. Service Q., 16: 51-77. DOI: 10.1108/09604520610639964

Kim, S.Y. and Y.L. Lim, 2001. Consumers' perceived importance of and satisfaction with Internet shopping. J. Electronic Markets, 11: 149-154. DOI: 10.1080/101967801681007988

Kimery, K.M. and M. McCord, 2002. Third party assurances: Mapping the road to trust in eRetailing. J. Inform. Technol. Theory Applic., 4: 63-82.

Kroeber, A. and C. Kluckhohn, 1952. Culture. 1st Edn., Meridian Books, New York.

Kumar, N., L. Scheer and J. Steenkamp, 1995. The effects of supplier fairness on vulnerable resellers. J. Market. Res., 17: 54-65. DOI: 10.2307/3152110

Kumar, N., L.K. Scheer and J.E.M. Steenkamp, 1998. Interdependence, punitive capability and the reciprocation of punitive actions in channel relationships. J. Market. Res., 35: 225-3. DOI: $10.2307 / 3151850$

Lee, G.G. and H.F. Lin, 2005. Customer perceptions of e-service quality in online shopping. Int. J. Retail Distribut. Manage., 33: 161- 176. DOI: 10.1108/09590550510581485

Leung, K., R.S. Bhagat, N.R. Buchan, M. Erez and C.B. Gibson, 2005. Culture and international business: recent advances and their implications for future research. J. Int. Bus. Stud., 36: 357-378. DOI: 10.1057/palgrave.jibs. 8400150

Li, N. and P. Zhang, 2002. Consumer online shopping attitudes and behavior: An assessment of research. Proceedings of 8th American Conference on Information Systems, (CYS’ 02), pp: 508-517.

Lim, K.H., C.L. Sia, M.K. Lee and I. Benbasat, 2006. Do I trust you online and if so, will I buy? An empirical study of two trust-building strategies. J. Manage. Inform. Syst., 23: 233-266. OI: 10.2753/MIS07421222230210
Loiacono, E., R. Watson and D. Goodhue, 2002. WebQual: A measure of Web site quality.

Lopez-Claros, A., 2006. Global information technology report 2005-2006. 1st Edn., Palgrave Macmillan, New York.

Lowry, P., A. Vance, G. Moody, B. Beckman and A. Read, 2008. Explaining and predicting the impact of branding alliances and web site quality on initial consumer trust of e-commerce web sites. J. Manage. Inform. Syst., 24: 199-224. DOI: 10.2753/MIS07421222240408

Lynch, P., R. Kent and S.S. Srinivasan, 2001. The global internet shopper: Evidence from shopping tasks in twelve countries. J. Advert. Res., 41: 15-23.

Madu, C. and A. Madu, 2002. Dimensions of e-quality. Int. J. Q. Reliability Manage., 19: 246-258. DOI: 10.1108/02656710210415668

Malhotra, N.K., F.M. Ulgado, J. Agarwal and I.B. Baalbaki, 1994. International services marketing: a comparative evaluation of the dimensions of service quality between developed and developing countries. Int. Market. Rev., 11: 5-15. DOI: 10.1108/02651339410061937

Malhotra, N.K., F.M. Ulgado, J. Agarwal, G. Shainesh and L. Wu, 2004. Dimensions of service quality in developed and developing economies: Multi-country cross-cultural comparisons. Int. Market. Rev., 22: 256-278. DOI: 10.1108/02651330510602204

Mao. D., 2010. A study of consumer trust in internet shopping and the moderating effect of risk aversion in Mainland China. Dissertation Hong Kong, Baptist University.

Marcus, A. and E.W. Gould, 2000. Crosscurrents: Cultural dimensions and global Web user-interface design. Interactions, 7: 32-46. DOI: 10.1145/345190.345238

Martin, S.S. and C. Camarero, 2008. Consumer trust to a web site: Moderating effect of attitudes toward online shopping. Cyber Psychol. Behav. Soc. Network. J., 11: 549-554. DOI: 10.1089/cpb.2007.0097, PMID: 18657047

Martin, S.S. and C. Camarero, 2009. How perceived risk affects online buying. Online Inform. Rev., 33: 629654. DOI: 10.1108/14684520910985657

Mayer, R.C., J.H. Davis and F.D. Schoorman, 1995. An integrative model of organizational trust. Acad. Manage. Rev., 20: 709-734. DOI: 10.5465/AMR.1995.9508 
McAllister, D.J., 1995. Affect- and cognition-based trust as foundations for interpersonal cooperation in organizations. Acad. Manage. J., 38: 24-59. DOI: 10.2307/256727

McKnight, D.H., L.L. Cummings and N.L. Chervany, 1998. Initial trust formation in new organizational relationships. Acad. Manage. Rev., 23: 473-490. DOI: $10.5465 / A M R .1998 .9266$

Mekovec, R., G. Bubas and N. Vrcek, 2007. A method for improvement of objectivity of e-service quality evaluation. J. Inform. Organiz. Sci., 31: 15-27.

Metehan, T. and Z.A. Yasemin, 2011. The effect of web vendor trust on Turkish online shoppers buying behavior. Austral. J. Bus. Manage. Res., 1: 87-96.

Metzger, M.J., 2006. Effects of site, vendor and consumer characteristics on web site trust and disclosure. Commun. Res., 33: 155-179. DOI: 10.1177/0093650206287076

Moorman, C., R. Deshpande and G. Zaltman, 1993. Factors affecting trust in market research relationships. J. Market., 57: 81-101. DOI: 10.2307/1252059

Morgan, R.M. and S.D. Hunt, 1994. The commitmenttrust theory of relationship marketing, J. Market., 58: 20-38. DOI: 10.2307/1252308

Morris, J.D., C. Woo, J.A. Geason and J. Kim, 2002. The power of affect: Predicting intention. J. Advert. Res., 3: 7-17.

Nunkoo, R., T.D. Juwaheer and T. Rambhunjun, 2013. Applying the extended technology acceptance model to understand online purchase behavior of travelers. Proceedings of 21st International Business Research Conference, Jun. 10-11, Ryerson University, Toronto, Canada.

Ojo, O., 2010. The relationship between service quality and customer satisfaction in the telecommunication industry: Evidence from Nigeria. BRAND, 1: 88100.

Othman, A. and L. Owen, 2001. Developing an Instrument to measure customer Service Quality (SQ) in Islamic banking. Int. J. Islamic Financial Services, 3: 1-26.

Parasuraman, A., V.A. Zeithaml and A. Malhotra, 2005. E-S-Qual: a multiple-item scale for assessing electronic service quality. J. Service Res., 7: 213233. DOI: $10.1177 / 1094670504271156$

Park, C.H. and Y.G. Kim, 2003. Identifying key factors affecting consumer purchase behavior in an online shopping context. Int. J. Retail Distribut. Manage., 31: 16-29. DOI: 10.1108/09590550310457818
Pavlou, P., 2002. What drives electronic commerce, a theory of planned behaviour perspective. Proceedings of the Academy of Management Conference, (AMC' 02), Denver, CO, August.

Pavlou, P., 2003. Consumer acceptance of electronic commerce: Integrating trust and risk with the technology acceptance model. Int. J. Elect. Commerce, 7: 101-134.

Pavlou, P.A. and D. Gefen, 2004. Building effective online marketplaces with institution-based trust. Inform. Syst. Res., 15: 37-59. DOI: 10.1287/isre. 1040.0015

Pavlou, P. and L. Chai, 2002. What drives electronic commerce across cultures? A cross-cultural empirical investigation of the theory of planned behaviour. J. Electronic Commerce Res., 3: 240-253.

Pavlou, P., H. Liang and Y. Xue, 2007. Understanding and mitigating uncertainty in online exchange relationships: A principal-agent perspective. MIS Q., 31: 105-136.

Peter, J.P. and M.J. Ryan, 1976. An investigation of perceived risk at the brand level. J. Market. Res., 13: 184-188. DOI: $10.2307 / 3150856$

Peter, J.P. and L.X. Tarpey, 1975. A comparative analysis of three consumer decision strategies. J. Consumer Res., 2: 29-37. DOI: 10.1086/208613

Reichheld, F. and P. Schefter, 2000. E-loyalty: Your secret weapon on the Web. Harvard Bus. Rev., 78: 105-113.

Ring, S.M. and A. Van de Ven, 1992. Structuring cooperative relationships between organizations. Strategic Manage. J., 13: 463-498. DOI: 10.1002/smj.4250130702

Rowley, J., 2006. An analysis of the e-service literature: towards a research agenda. Internet Res., 16: 33959. DOI: $10.1108 / 10662240610673736$

Sahadev, S. and K. Purani, 2008. Modelling the consequences of e-service quality, Market. Intell. Plann., 26: 605-620. DOI: $10.1108 / 02634500810902857$

Santos, J., 2003. E-service quality: A model of virtual service quality dimensions. Jessica Santos, 131: 233-246.

Schiffman, L. and L. Kanuk, 1997. Consumer Behavior. 5th Edn., Prentice Hall.

Schiffman, M., P.E. Castle and J. Jeronimo, 2007. Human papillomavirus and cervical cancer. Lancet, 370: 890907. DOI: 10.1016/S0140-6736(07)61416-0 
Shih, H.P., 2004. An empirical study on predicting user acceptance of e-shopping on the Web. Inform. Manage., 41: 351-368. DOI: 10.1016/S03787206(03)00079-X

Shrout, P.E. and N. Bolger, 2002. Mediation in experimental and non experimental studies: New procedures and recommendations. Psychol. Methods, 7: 422-445. DOI: 10.1037/1082989X.7.4.422

Sigala, M., 2004. Designing experiential websites in tourism and hospitality: a customer-centric value approach. Free University of Bolzano.

Sigala, M. and O. Sakellaridis, 2004. Web users' cultural profiles and e-service quality: Internationalization implications for tourism WEB sites. Inform. Technol. Tourism, 7: 13-22. DOI: 10.3727/1098305042781101

Sohn, C. and S.K. Tadisina, 2008. Development of eservice quality measure for internet-based financial institutions. Total Q. Manage. Bus. Excell., 19: 903918. DOI: $10.1080 / 14783360802224412$

Sonja, G.K., 2002. The Role of consumers' trust in online-shopping. J. Bus. Ethics, 39: 43-50. DOI: 10.1023/A:1016323815802

Straub, D.W., D.L. Hoffman, B.W. Weber and C. Steinfied, 2002. Toward new metrics for netenhanced organizations. Inform. Syst. Res., 13: 227238. DOI: $10.1287 /$ isre.13.3.227.80

Surjadaja, J., S. Ghosh and F. Antony, 2003. Determining and assessing the determinants of e-service operations. Manag. Service Q., 13: 39-53. DOI: $10.1108 / 09604520310456708$

Tahir, I.M. and W.Z.W. Ismail, 2004. Customer service quality in insurance industry: The case of Islamic insurance. Proceedings of the International Borneo Business Conference, (BBC' 04), Kota Kinabalu, Sabah, Malaysia. December, pp: 9-11.

Tan, F.B. and P. Sutherland, 2004. Online consumer trust: A multi-dimensional model. J. Electronic Commerce Organiz., 2: 40-58. DOI: 10.4018/jeco.2004070103

Tan, M. and T.S.H. Teo, 2000. Factors influencing the adoption of Internet banking. J. Assoc. Inform. Syst.

Taylor, J.W., 1974. The role of risk in consumer behavior. J. Market., 39: 54-60. DOI: $10.2307 / 1250198$

Tsikriktsis, N., 2002. Does culture influence web site quality expectations? An empirical study. J. Service Res., 5: 101-12. DOI: 10.1177/109467002237490
Ueltschy, L.C., M. Laroche, M. Zhang, H. Cho and R. Yingwei, 2009. Is there really an Asian connection? Professional service quality perceptions and customer satisfaction. J. Bus. Res., 62: 972-979. DOI: 10.1016/j.jbusres.2008.03.003

Verhagen, T., S. Meents and Y. Tan, 2006. Perceived Risk and Trust Associated with Purchasing at Electronic Marketplaces, Serie Research Memoranda 0001, Faculty of Economics, Business Administration and Econometrics, Free University Amsterdam, Amsterdam.

Vlachos, P. and A. Vrechopoulos, 2008. Determinants of behavioral intentions in the mobile internet services market. J. Services Market., 22: 280-291. DOI: 10.1108/08876040810881687

Wakefield, R.J., M.H. Stocks and W.M. Wilder, 2004. The role of web site characteristics in initial trust formation. J. Comput. Inform. Syst., 45: 94-103.

Wolfinbarger, M. and M.C. Gilly, 2003. ETailQ: dimensionalizing, measuring and predicting etail quality. J. Retail., 79: 183-198. DOI: 10.1016/S0022-4359(03)00034-4

Wu, I.L. and J.L. Chen, 2005. An extension of Trust and TAM model with TPB in the initial adoption of online tax: An empirical study. Int. J. Human, 62: 784808. DOI: 10.1016/j.ijhcs.2005.03.003

Yang, Z. 2001. Consumer perceptions of service quality in Internet-based electronic commerce, EMAC Conference, 8-11 May 2001, Bergen.

Yen, H.J.R. and K.P. Gwinner, 2003. Internet retail customer loyalty: the mediating role of relational benefits. Int. J. Service Industry Manage., 14: 483500. DOI: 10.1108/09564230310500183

Yoo, B., N. Donthu and T. Lenartowicz, 2001. Individual Cultural Values: A Multi-Country Investigation. School of Business, Hofstra University. Hempstead.

Yoon, S., 2002. The antecedents and consequences of trust in online-purchase decisions. J. Interactive Market., 12: 47-63. DOI: 10.1002/dir.10008

Zeithaml, V. A. A. Parasuraman and A. Malhotra, 2002. A Conceptual Framework for Understanding eService Quality: Implications for Future Research and Managerial Practice, Marketing Science Institute, Inc., pp. 00-115.

Zeithaml, V.A., 2002. Service excellence in electronic channels. Manag. Service Q., 12: 135-138. DOI: $10.1108 / 09604520210429187$ 
Zeithaml, V.A., A. Parasuraman and A. Malhotra, 2000. A conceptual framework for understanding e-service quality: Implications for future research and managerial practice. Marketing Science Institute, Cambridge. MA.

Zhang, X. and V.R. Prybutok, 2005. A consumer perspective of e-service quality. IEEE Trans. Eng. Manage., 52: 461-477. DOI: 10.1109/TEM.2005.856568

Zhang, X. and Y. Tang, 2006. Customer perceived eservice quality in online shopping. Dissertation. Lulea University of Technology.
Zhao, X., C. Bai and Y.V. Hui, 2002. An empirical assessment and application of SERVQUAL in a mainland Chinese department store. Total Q. Manage., 13: 241-254. DOI: $10.1080 / 09544120120102478$

Zhou, T., S. Zhang and B. Ji, 2010. Exploring the effect of online banking service quality on users' continuance usage. Proceedings of the 2nd International Conference on e-Business and Information System Security, May 22-23, IEEE Xplore Press, Wuhan, pp: 1-4. DOI: 10.1109/EBISS.2010.5473471 